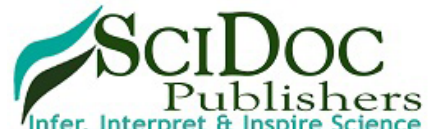

International Journal of Dentistry and Oral Science (IJDOS) ISSN: 2377-8075

\title{
Evaluating The Effect Of Pressure Exerted During Mechanical Cord Packing Using A Custom-Made Pressure Indicating Device - A Randomised Clinical Trial
}

Research Article

Abinaya Kannan ${ }^{1}$, Suresh Venugopalan ${ }^{2 *}$

${ }^{1}$ Saveetha Dental College And Hospitals, Saveetha Institute of Medical And Technical Sciences(SIMATS), Saveetha University, Chennai, India. ${ }^{2}$ Professor, Saveetha Dental College And Hospitals, Saveetha Institute of Medical And Technical Sciences(SIMATS), Saveetha University, Chennai, India.

Abstract

Preservation of periodontium is a vital factor in tooth preparation and soft tissue management. The force exerted while performing cord packing and its effect on the periodontium is an aspect that remains unexplored. The aim of the study was to evaluate the effect of pressure exerted by cord packing on the supporting structures at varying levels of pressure exerted by Graduate students. Pressure exerted while performing cord packing was evaluated using a custom-made instrument. 40 sites were evaluated for gingival recession (Labial and Lingual) and 80 sites were evaluated for probing depth and bleeding on probing (Labial, Lingual, Mesial, Distal) pre-operatively (Day 0) and post operatively (Day 4, Day 7, Day 14, Day 30). Statistical analysis such as ROC Curve (optimal pressure value), Kruskal Wallis, Mann-Whitney and Bonferroni Adjusted Wilcoxon Rank Test (associated gingival and periodontal changes) were performed.

The threshold value at which cord packing can be performed safely is $1.05 \mathrm{~Pa}$. While gingival recession ranged from $0.5 \mathrm{~mm}$ to $3 \mathrm{~mm}$ at Day 30; with increased pressure, bleeding on probing and probing depth elicited an initial increase followed by a decline. The study indicated Cord packing can be performed clinically at / below 1.05Pa pressure to prevent harmful effects on the periodontium. Maximum pressure value exerted was 5.7Pa, hence an improvised cord packer with an audio-visual feedback at threshold limit might facilitate to perform controlled cord packing.

Keywords: Bleeding On Probing; Cord Packing; Cord Packing Pressure; Probing Depth; Gingival Recession.

\section{Introduction}

A successful replacement with fixed partial denture accounts to many factors [1-3]. Marginal fit is one of the vital factors dictating the prognosis of the prosthesis. It is hence essential to record the prepared and unprepared surfaces of the abutment with absolute precision [4]. Proper retraction is as important as that of the impression material used and its properties [5-7] Various methods of retraction include mechanical, chemical \& chemo mechanical, rotary and laser [6, 8-14].

Though many studies had been performed on the material aspects, on the retraction efficiency and on the precision of recording the clinically prepared abutment teeth; $[4,7-15]$ the force with which the retraction cord is packed into the sulcus and its effect on gingival health is still untouched. Pressure applied while pack- ing gingival retraction cords have not been assessed and is not available in the literature.

Its effects should hence be assessed to establish a threshold at which good marginal integrity is achieved without eliciting deleterious effects on the supporting structures resulting in a successful restoration.

The objectives of the study performed were to evaluate the maximum and minimum force generated to place a gingival retraction cord and to assess associated gingival and periodontal changes.

\section{Subjects and Methods}

The study performed was in accordance with the ethical standards of the Institution Scientific Review Board (SRB Ref No: SRB/

*Corresponding Author

Dr. Suresh Venugopalan,

Professor, Saveetha Dental College And Hospitals, Saveetha Institute of Medical And Technical Sciences(SIMATS), Saveetha University, Chennai, India. Tel: 9543192858

E-mail: suresh@saveetha.com

Received: May 04, 2021

Accepted: June 05, 202

Published: June 14, 2021

Citation: Abinaya Kannan, Suresh Venugopalan. Evaluating The Effect Of Pressure Exerted During Mechanical Cord Packing Using A Custom-Made Pressure Indicating Device - A Randomised Clinical Trial. Int J Dentistry Oral Sci. 2021;8(6):2698-2705. doi: http://dx.doi.org/10.19070/2377-8075-21000526

Copyright: Suresh Venugopalan ${ }^{\circ} 2021$. This is an open-access article distributed under the terms of the Creative Commons Attribution License, which permits unrestricted use, distribution and reproduction in any medium, provided the original author and source are credited. 
SDMDS16PRS/05) and an informed consent was obtained from each of the study participants. From "Power and Sample Size for Dose Response Studies" by Chang et al (2006) the number of sites to be evaluated in terms of pressure-recession as dose-response for our current study was arrived at 28 (Chang and Chow 2006). The study was registered in Clinical Trials Registry - India (Registration Number: CTRI/2019/05/018925). Data collection form was customized to comprise two portions, namely, the demographic data (Serial Number, Patient's Name, Age, Address \& Contact Number), the clinical data (Missing tooth, Abutment Teeth, Operator's Name \& Clinic, Contact Number, Dates of evaluation - Day 0, Day 4, Day 7, Day 14) and the parameters analysed (gingival status, periodontal status, gingival recession/ crown height, pressure exerted while performing gingival retraction cord packing procedure - recorded at various sites and at corresponding time intervals).

A double - blinded randomized clinical trial was performed on 20 patients (simple randomization) who reported to the university dental clinics with periodontally sound abutments and a single missing tooth requiring replacement with a fixed partial denture. There was no allocation ratio as this was a simple randomized prospective clinical trial. Cases with more than one missing tooth but indicated for fixed partial denture, having questionable periodontal status with clinical mobility, presence of pockets and furcation involvement, abutment teeth with clinically evident gingival proliferation or enlargement were excluded.

80 sites of periodontally sound abutment teeth (anterior and posterior abutments), fit for harbouring a fixed dental prosthesis and replacing a single missing tooth were considered in this study. All patients were treated by Under Graduate students. In the initial diagnostic visit, Bleeding on Probing (Sulcular Bleeding Index), Probing Depth and the crown height (from marginal gingiva to the highest portion of the crown midbuccally and midlingually) were evaluated using a blunt William's periodontal probe. Post tooth preparation, students were then asked to perform routine cord packing procedure (Fig. 1) with the custom-made pressure indicating device (Fig. 2) prior to making the master impression and pressure values at the deepest point at four sites (labially, lingually, mesially and distally) of the abutment teeth were recorded.

\section{Construction of the custom-made device}

A cord packer is sectioned and a sensor is mounted onto a tip made of sterilizable stainless steel. The sensor is then connected to a whetstone network which works on power supply and hence displays the amount of pressure exerted in digital display.

\section{Working/Mechanism}

The pressure exerted at the tip of the cord packing instrument is perceived by the sensor. The mechanical energy is then converted to electrical impulses and is transmitted via a whetstone network. When the cord packer is pressed against the tissue, there is an imbalance in the bridge (in terms of millivolts). The output is further conditioned, linearized, amplified and given as an input to the digital display. The display accepts the electrical output of the conditioned signal and displays the pressure exerted in terms of Pascals.

\section{Gingival Status}

The gingival status of the abutment teeth was assessed by evaluating the bleeding on probing by walking a William's Periodontal Probe on the abutment teeth at four different sites (labial, lingual, mesial, distal) at day 0, day 1, day 4, day 7 and day 14. Based on the sulcus bleeding index (SBI) the sites were scored. (Fig. 3)

\section{Periodontal Status}

The periodontal status of the abutment teeth was assessed by recording the periodontal probing depth using William's Periodontal Probe at the mid-point of labial, lingual, mesial and distal surfaces at every visit. (Fig. 4)

\section{Gingival Recession}

Initially, the clinical crown height was measured using a William's periodontal probe from the marginal gingiva to the highest point of the anatomical crown of the abutment in the mid-buccal and the mid-lingual region and recorded in the diagnostic visit.

In the subsequent visits, gingival recession was measured at dif-

Figuer 1. Gingival Retraction cord.

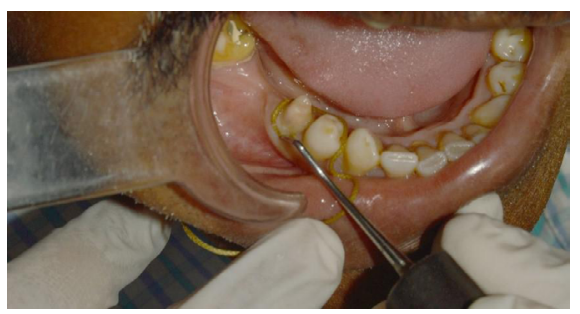

Figuer 2. Custom-made Cord Packer.

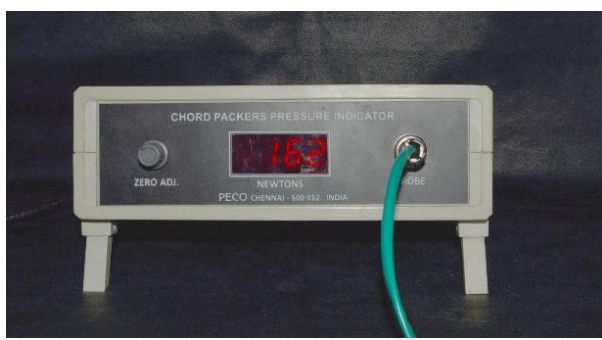


Figuer 3. Evaluation of Bleeding on Probing.

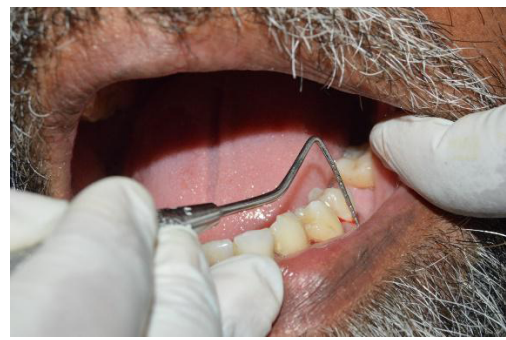

Figuer 4. Evaluation of probing depth.

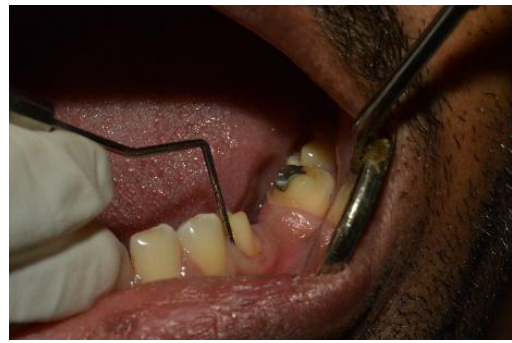

Figuer 5. Evaluation of Gingival Recession Labially.

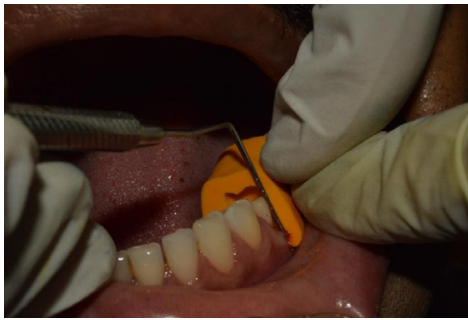

Figuer 6. Evaluation of Gingival Recession Lingually.

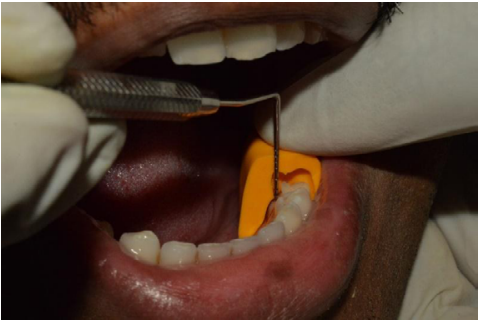

ferent time intervals by two methods. In the first method, a putty index of the edentulous site and the abutment teeth were made from the diagnostic cast. The index was then sectioned at the middle-third of the abutment teeth into three individual units. Gingival recession at mid-buccal and mid-lingual portions were evaluated by measuring the distance between marginal gingiva and the highest portion of the unprepared abutment tooth as evident from the putty index in place. The sectioned portions were placed over the prepared teeth and height measurement was done accordingly. This evaluation was done in day 1 , day 4 and day 7 . The difference between the crown height measured on day 1 and that measured in day 4 / day 7 gave the amount of recession evident on that day in millimetres. (Fig. 5 \& 6)

In the second method, the distance between the marginal gingiva and the margin of the preparation were evaluated using a William's periodontal probe and recorded. This evaluation was done in all visits following tooth preparation viz. day 1 , day 4 , day 7 and day 14

\section{Statistical Analysis}

The Normality of the study was evaluated using Kolmogorov-
Smirnov and Shapiro-Wilks tests. The optimal pressure at which cord packing can be performed without bringing about gingival recession was evaluated by plotting a Receiver Operating Characteristic Curve. Kruskal Wallis, Mann-Whitney and Bonferroni Adjusted Wilcoxon Rank Test were performed to assess the associated gingival (bleeding on probing and probing depth) and periodontal changes (gingival recession). SPSS (IBM SPSS Statistics for Windows, Version 22.0, Armonk, NY: IBM Corp. Released 2013) was used to analyse data. Significance level was fixed as $5 \%$ $(\alpha=0.05)$.

\section{Results}

The optimal pressure at which cord packing can be performed without bringing about gingival recession was evaluated by plotting a Receiver Operating Characteristic Curve (Fig. 7)

From the ROC curve obtained it is evident that the test shows more accuracy as the curve follows the left-hand border and the top border of the ROC space. Also, the curve being farther away from the 45-degree diagonal of the ROC space indicates the same. The area under the curve means discrimination. i.e. the ability of 
the test to correctly classify those subjects with disease and those without disease. The area under the curve obtained being 0.909 indicates excellent accuracy. In the current study, optimal pressure at which cord packing can be performed without bringing about detrimental effects to the supporting structures has been determined to be $1.05 \mathrm{~Pa}$. (Table $1 \& 2$ )

The maximum and minimum pressure exerted by under graduate dental students while performing cord packing procedure was found to be a maximum of $5.7 \mathrm{~Pa}$ and a minimum of $0.22 \mathrm{~Pa}$ (Fig. 9)

Probing depth values and bleeding on probing values at four sites at different time intervals showed an initial rise from the diagnostic visit peaking at Day 4 corresponding to cord packing followed by decline indicating the initial phase of trauma induced by pressure exerted during gingival retraction cord packing and the subsequent phase of healing. (Fig. $10 \& 11$ )

In terms of gingival recession, the amount of recession from base value (measured at diagnostic visit Day 0) was found to peak at Day 4 corresponding to cord packing. Though there was a decline from the peak value, there was a substantial level of gingival re- cession observed with varying amounts of pressure denoting irreversible damage caused as indicated by the curves not returning to base value. (Fig. 12)

\section{Discussion}

Gingival retraction has been a vital procedure that determines the outcome of the fabricated prosthesis in terms of marginal fit [16]. Recording the unprepared surface in the impression plays an important role in the quality of the prosthetic outcome [17]. It is a key factor that is essential to achieve precise marginal fit and hence eliminate food lodgement, subsequent plaque formation and consequential development of secondary caries of the abutment teeth.

Among the various methods available for gingival retraction, mechanical cord packing procedure is most preferred and widely used [18]. In a study performed by Moldi A et al, 2013, 72.8\% of practitioners in India had reported performing mechanical cord packing for gingival retraction [19]. A majority of practitioners $(92 \%)$ in US and Canada perform gingival retraction by cord packing procedure [8]. Carlos Barrero et al (2015) had reported that the third and fourth year under graduate students of Chapel

Figuer 7. Depicts ROC curve plotted on (1-Specificity) against Sensitivity to obtain the optimal pressure value at / under which cord packing can be done without eliciting the detrimental effects on the supporting structures..

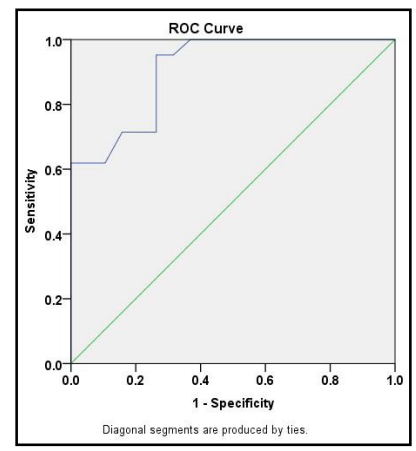

Figuer 8. Comparison of Mean Pressure (Pa) exerted at each site (Labial, Lingual, Mesial, Distal).

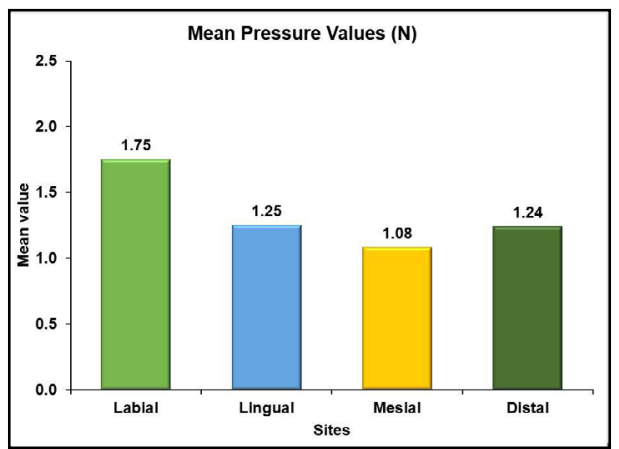

Figuer 9. Assessment of maximum and minimum pressure exerted (in Newtons).

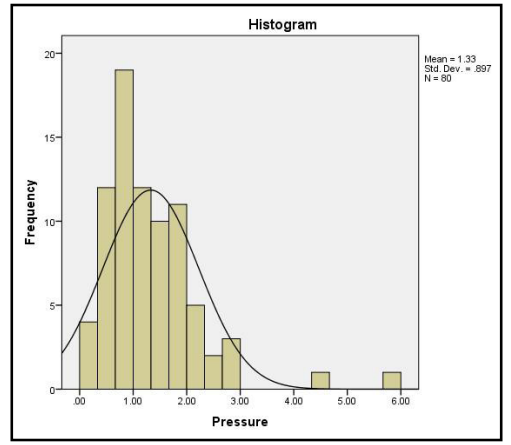


Figuer 10. Comparison of Mean Probing Depth(mm) exerted at each site (Labial, Lingual, Mesial, Distal).

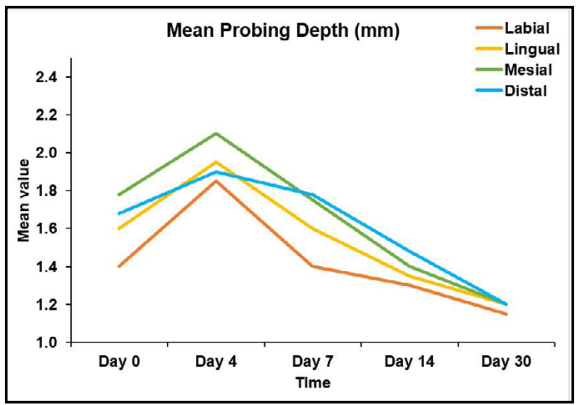

Figuer 11. Comparison of Mean Presence of Bleeding on Probing observed at different time points (Day 0, Day 4, Day 7, Day 14, Day 30).

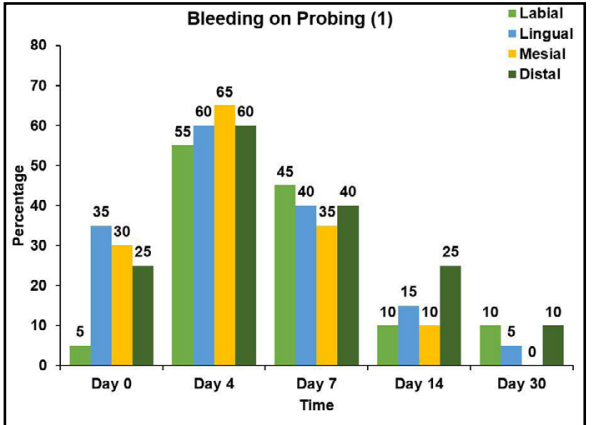

Figuer 12. Comparison of Mean Gingival Recession (mm) observed between time points (Day 0, Day 4, Day 7, Day 14, Day 30).

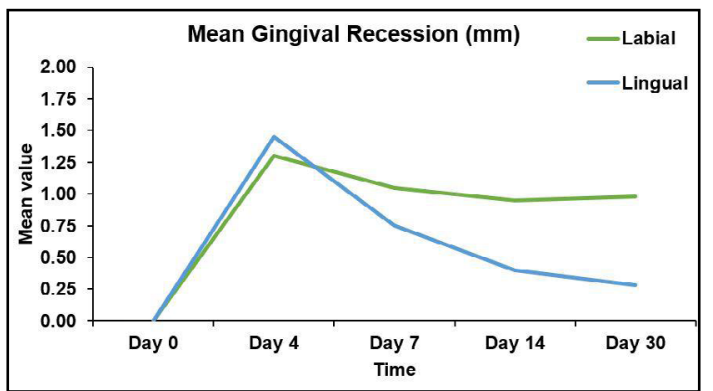

Figuer 13. Characteristic Gingival Recession observed.

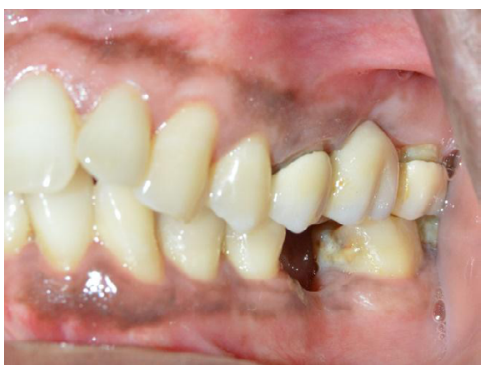

Hill School of Dentistry, University of North Carolina agreed that $68 \%$ of them performed mechanical cord packing effectively [20].

Dental school students, in their training period are emphasized to follow the principles of tooth preparation. Among the various principles, preservation of periodontium is one of the vital factors determining the prognosis of the fixed prosthesis and associated periodontal health around the abutment. The effect of mechanical cord packing on the associated supporting structures have been evaluated in comparison with other methods of gingival retraction in the past [21]. However, the amount of pressure exerted while performing mechanical cord packing has neither been calibrated nor their corresponding changes in the supporting structures were evaluated.
The present study indicates that an operator may exert a minimum of $0.22 \mathrm{~Pa}$ to a maximum of $5.7 \mathrm{~Pa}$ using a cord packer instrument towards the gingival sulcus during the cord packing procedure. With highest force value detected during cord packing in buccal gingival sulcus of posterior tooth and least cord packing force used in anterior labial gingival sulcus. During diagnostic procedures, the reported periodontal force to be used on gingival or periodontal assessment is anywhere between $0.5 \mathrm{~Pa}$ to $1.25 \mathrm{~Pa}$. [22]. Values obtained in the present study indicated a variation which can be excessive and unfavourable in comparison to the periodontal health studies.

On performing a ROC Curve analysis, a value of $1.05 \mathrm{~Pa}$ was obtained as a threshold at which gingival retraction cord packing 
Table 1. Area Under the Curve.

\begin{tabular}{|c|c|c|c|c|}
\hline Area & \multirow{2}{*}{$\begin{array}{c}\text { Std. Er- } \\
\text { ror }\end{array}$} & P-Value & \multicolumn{2}{|c|}{$\begin{array}{c}\text { Asymptotic 95\% Confidence } \\
\text { Interval }\end{array}$} \\
\cline { 4 - 5 } & & & Lower Bound & Upper Bound \\
\hline 0.909 & 0.045 & $<0.001$ & 0.821 & 0.996 \\
\hline
\end{tabular}

Table 2. Evaluation of sensitivity, specificity and diagnostic accuracy.

\begin{tabular}{|c|c|c|c|c|c|}
\hline & & \multicolumn{3}{|c|}{ Gingival Recession } & \multirow[t]{2}{*}{ Total } \\
\hline & & Present $(>=1)$ & & & \\
\hline \multirow[t]{2}{*}{ Pressure Values $(\mathrm{Pa})$} & $>1.05$ & 13 & \multicolumn{2}{|c|}{0} & 13 \\
\hline & $<1.05$ & 8 & \multicolumn{2}{|c|}{19} & 27 \\
\hline \multicolumn{2}{|l|}{ Total } & 21 & 19 & 40 & \\
\hline
\end{tabular}

\begin{tabular}{|c|c|c|}
\hline Parameter & Estimate & Lower - Upper 95\% CIs \\
\hline Sensitivity & $61.90 \%$ & $(40.88,79.25)$ \\
\hline Specificity & $100 \%$ & $(83.18,100)$ \\
\hline Positive Predictive Value & $100 \%$ & $(77.19,100)$ \\
\hline Negative Predictive Value & $70.37 \%$ & $(51.52,84.15)$ \\
\hline Diagnostic Accuracy & $80 \%$ & $(65.24,89.5)$ \\
\hline
\end{tabular}

Table 3. Descriptive Statistics - Maximum and Minimum Pressure Values.

\begin{tabular}{|c|c|c|c|c|c|c|c|}
\hline & $\mathbf{N}$ & Range & Minimum & Maximum & \multicolumn{2}{|c|}{ Mean } & Std. Deviation \\
\cline { 2 - 8 } & Statistic & Statistic & Statistic & Statistic & Statistic & Std. Error & Statistic \\
\hline Pressure & 80 & 5.48 & 0.22 & 5.7 & 1.329 & 0.100 & 0.897 \\
\hline Valid N (listwise) & 80 & & & & & & \\
\hline
\end{tabular}

can be performed within safe limits. A value less than/equal to 1.05 Pa did not exhibit gingival recession clinically on Day 30 . The test result had a sensitivity of $61.9 \%$, specificity of $100 \%$ and a diagnostic accuracy of $80 \%$ and it was statistically significant $(\mathrm{P}$ value $<0.001)$

In a study performed by Velden et al, (1979) on evaluation of pressure elicited by periodontal probe in patients with periodontal pathology, an optimum value of only $0.75 \mathrm{~Pa}$ towards the gingival sulcus was indicated as favorable and appropriate [22]. The variation in the cord packing force from the former probing force can be due to the accessibility to the abutment teeth (anterior or posterior region), the cord packing technique in itself which involves a gentle force required for placing or positioning the cord into the gingival sulcus which sometimes may be exceeded without the operator's knowledge.

When evaluating gingival recession, characteristic findings in the current study was a v-shaped notch like defect (crescent shaped in a few instances), predominantly occurring in the labial aspect of the tooth with little to no recession of the interdental papilla (Fig. 13). On the labial aspect post-cord packing day i.e., after Day 4, there is a decreasing trend of the gingival recession values on Day 7, Day 14 and Day 30. Statistically there is a significant difference between Day 0 to Day 4 and Day 7 (P value $<0.001$ ) indicating a definitive effect of recession happening on the day of cord packing and the succeeding week in comparison to the gingival health prior to cord packing. In the current study, graduate students had exerted pressure above the optimum level in 43 instances and findings from a minimum of $0.5 \mathrm{~mm}$ gingival recession to a maximum of $3 \mathrm{~mm}$ was observed at Day 30 .

The most recent classification of periodontal diseases includes a new section on traumatic gingival lesions [23]. Traumatic lesions are thought to be highly prevalent, but it remains to be a topic that is not widely discussed in the literature [24]. The recession observed in the current study due to cord packing can be like that observed with the features mentioned with physical trauma caused due to malocclusion (labial), trauma observed in RPD wearers and tooth brush trauma [24-26].

The gingival recession was more prone in thin gingival biotype and the recession had a characteristic feature of traumatic stripped type of gingiva. This stripping type of gingival recession features had similarities to the gingival recession types mentioned in the study performed by Paul S. Wright et al. [26].

While evaluating probing depth to assess the effect of cord packing, an increasing trend in the first half and a decreasing trend in the second half of the study was observed. Statistically significant variations were observed between Day 4 vs Days 14, 30 and Day 7 vs Day 30 ( $\mathrm{P}$ value $<0.001$ ). This may be due to observation of the highest value of probing depth obtained immediately after the impression is made (Day 4), which shows decline in the subsequent days (Day 7, Day 14, Day 30). Periodontal probing depth was found to be less than $3 \mathrm{~mm}$ in all instances at Day 30 and this 
may be attributed to the absence of periodontal disease and indicate that recession is purely because of trauma [24].

Bleeding on probing was found to be present consistently at all instances in Day 4 which may be due to the cord packing procedure. However, it was absent on Day 0 and slowly declined subsequently in Days 7, 14 and 30. This explains the gradient observed which is like that observed in terms of probing depth. In a study performed by Feng a similar gradient was observed in terms of gingival inflammation. However, similar changes in bleeding on probing was not reported in his study. Association between Bleeding on Probing observed at varying points of time showed statistical significance in Day 0 vs Day 30 (P value $=0.004$ ), Day 7 vs Day 14 , Day 30 ( $\mathrm{P}$ value $<0.001)$. Bleeding on probing is a predictor of gingival inflammation and periodontal disease. Its absence at Day 30 coupled with periodontal probing depth being less than $3 \mathrm{~mm}$ strongly suggests that gingival recession observed in the study can be due to trauma inflicted to the sulcular epithelium while performing cord packing with inadvertent forces. In a study performed by Acar et al, 2014, gingival retraction performed with retraction cap with paste group (Hemodent paste) showed better results in terms of bleeding than the aluminium chloride impregnated cord group $(\mathrm{P}<.008)$ [4]. In studies performed by Chandra et al, Al Hamad et al and Kazemi et al, bleeding index was greater in mechanical cord packing than in cordless paste group [27-29]. On the contrary, Sarmento et al, in his study stated that no significant difference in terms of bleeding on probing was observed between mechanical retraction and use of retraction pastes during or after gingival retraction [30]. In his study, de Gennaro et al, 1982, gingival inflammation associated with chemo mechanical retraction observed was of order 8\% Racemic Epinephrine $>$ Aluminium Sulphate $>$ Potassium Aluminium Sulphate [31].

This study had a prospective design over a limited period. Extensive studies and long-term follow up (3-5 years) over a wider range of samples within the prescribed range of pressure might give more precise values and significant clinical outcomes associated with the studies. Further variation in pressure levels by male and female operators on male and female subjects with varying biotypes can also be performed.

The current study shows the effect of cord packing performed at varying levels of pressure and their subsequent effects in the supporting structures. Further, studies focussing on the application of pressure in patients with compromised periodontal status might help accomplishing cord packing in safe limits in scenarios with moderate periodontal conditions where inclusion of additional abutments may be required. Improvisation of the instrument to a portable version with an audio-feedback at threshold might help guiding the clinicians and students in channelizing the pressure exerted while performing cord packing at ease.

\section{Conclusion}

The need for a digitally measuring device is a must while performing procedures on soft tissues. The operator's retraction techniques or subsequent pressure applied during cord packing procedure can be restricted to $1.05 \mathrm{~Pa}$ or lesser than that. Any excessive pressure exerted by the operator during the cord packing procedure can result in gingival recession which sometimes may be irreversible. Developing a handy instrument with threshold value can be a real training guide for the amateur operators.

Clinical Relevance: Amount of pressure exerted is a significant factor leading to gingival recession and hence affecting the prognosis. Modifying the instrument to a portable version with an audio-feedback at threshold might facilitate the clinicians and students in channelizing the pressure exerted while performing cord packing at ease.

\section{References}

[1]. Hobkirk JA. Prosthodontics: a past with a future. J Can Dent Assoc. 2005 May;71(5):326.

[2]. Bouchard P, Renouard F, Bourgeois D, Fromentin O, Jeanneret MH, Beresniak A. Cost-effectiveness modeling of dental implant vs. bridge. Clinical oral implants research. 2009 Jun 1;20(6):583-7.

[3]. Johnston JF, Phillips RW, Dykema RW. Modern practice in crown and bridge prosthodontics. WB Saunders Company; 1971.

[4]. Acar Ö, Erkut S, Özçelik TB, Ozdemır E, Akçil M. A clinical comparison of cordless and conventional displacement systems regarding clinical performance and impression quality. Journal of Prosthetic Dentistry. 2014 May 1;111(5):388-94.

[5]. Hansen PA, Tira DE, Barlow J. Current Methods of Finish-Line Exposure by Practicing Prosthodontists. Journal of Prosthodontics. 1999 Sep 1;8(3):163-70.

[6]. Harrison JD. Effect of retraction materials on the gingival sulcus epithelium. Journal of prosthetic Dentistry. 1961 May 1;11(3):514-21.

[7]. Ramadan FA. The linear effectiveness of dental tissue displacement materials. St. Louis: St. Louis University Dental School. 1968.

[8]. Ahmed SN, Donovan TE. Gingival displacement: Survey results of dentists' practice procedures. Journal of Prosthetic Dentistry. 2015 Jul 1;114(1):81-5.

[9]. Al-Ani A, Bennani V, Chandler NP, Lyons KM, Thomson WM. New Zealand dentists' use of gingival retraction techniques for fixed prosthodontics and implants. NZ Dent J. 2010 Sep 1;106(3):92-6.

[10]. Kannan A, Venugopalan S, Ganapathy DM, Jain AR. A knowledge, attitude, and practice survey on" the methodology followed in the fabrication of fixed partial denture amongst private practitioners". Drug Invention Today. 2018 Aug $1 ; 10(8)$.

[11]. Gajbhiye V, Banerjee R, Jaiswal P, Chandak A, Radke U. Comparative evaluation of three gingival displacement materials for efficacy in tissue management and dimensional accuracy. The Journal of Indian Prosthodontic Society. 2019 Apr 1;19(2):173.

[12]. Thimmappa M, Bhatia M, Somani P, Kumar DR. Comparative evaluation of three noninvasive gingival displacement systems: An in vivo study. Journal of Indian Prosthodontic Society. 2018;18(2):122-30.

[13]. Gupta A, Prithviraj DR, Gupta D, Shruti DP. Clinical evaluation of three new gingival retraction systems: A research report. The Journal of Indian Prosthodontic Society. 2013 Mar 1;13(1):36-42.

[14]. Kannan A, Venugopalan S. A systematic review on the effect of use of impregnated retraction cords on gingiva. Research Journal of Pharmacy and Technology. 2018 May 1;11(5):2121-6

[15]. Ramadan FA, El-Sadeek M. Histopathologic response of gingival tissues to hemodent and aluminum chloride solutions as tissue displacement materials. Egyptian dental journal. 1972 Oct;18(4):337-52.

[16]. Ferencz JL. Maintaining and enhancing gingival architecture in fixed prosthodontics. The Journal of prosthetic dentistry. 1991 May 1;65(5):650-7.

[17]. Heintze SD. Systematic reviews: I. The correlation between laboratory tests on marginal quality and bond strength. II. The correlation between marginal quality and clinical outcome. Journal of Adhesive Dentistry. 2007 Jan 1;9(1).

[18]. Wassell RW, Barker D, Walls AW. Crowns and other extra-coronal restorations: impression materials and technique. British dental journal. 2002 Jun 29;192(12):679.

[19]. Moldi A, Gala V, Puranik S, Karan S, Deshpande S, Neela N. Survey of impression materials and techniques in fixed partial dentures among the practitioners in India. ISRN dentistry. 2013 Apr 22;2013.

[20]. Barrero C, Duqum I, Petrola F. Dental students' perceived preparedness to treat patients in clinic after a fixed prosthodontics course: survey results of a case study. Journal of dental education. 2015 Apr 1;79(4):409-16.

[21]. Tabassum S, Adnan S, Khan FR. Gingival retraction methods: a systematic review. Journal of Prosthodontics. 2017 Dec 1;26(8):637-43.

[22]. Velden U. Probing force and the relationship of the probe tip to the periodontal tissues. Journal of Clinical Periodontology. 1979 Apr 1;6(2):106-14.

[23]. Armitage GC. Development of a classification system for periodontal diseases and conditions. Annals of periodontology. 1999 Dec 1;4(1):1-6. 
[24]. Rawal SY, Claman LJ, Kalmar JR, Tatakis DN. Traumatic lesions of the gingiva: a case series. Journal of periodontology. 2004 May 1;75(5):762-9.

[25]. Litonjua, Luis A., Sebastiano Andreana, Peter J. Bush, and Robert E. Cohen. 2003. "Toothbrushing and Gingival Recession." International Dental Journal 53 (2): 67-72.

[26]. Wright PS, Hellyer PH. Gingival recession related to removable partial dentures in older patients. Journal of Prosthetic Dentistry. 1995 Dec $1 ; 74(6): 602-7$

[27]. Chandra S, Singh A, Gupta KK, Chandra C, Arora V. Effect of gingival displacement cord and cordless systems on the closure, displacement, and inflammation of the gingival crevice. Journal of Prosthetic Dentistry. 2016 Feb 1;115(2):177-82

[28]. Al Hamad KQ, Azar WZ, Alwaeli HA, Said KN. A clinical study on the effects of cordless and conventional retraction techniques on the gingival and periodontal health. Journal of clinical periodontology. 2008 Dec 1;35(12):1053-8.

[29]. Kazemi M, Memarian M, Loran V. Comparing the effectiveness of two gingival retraction procedures on gingival recession and tissue displacement: clinical study. Research Journal of Biological Sciences. 2009;4(3):335-9.

[30]. Sarmento HR, Leite FR, Dantas RV, Ogliari FA, Demarco FF, Faot F. A double-blind randomised clinical trial of two techniques for gingival displacement. Journal of oral rehabilitation. 2014 Apr 1;41(4):306-13.

[31]. Landesman HM, Calhoun JE, Martinoff JT. A comparison of gingival inflammation related to retraction cords. The Journal of prosthetic dentistry. 1982 Apr;47(4):384-6 